\title{
Glucose-6-phosphate dehydrogenase deficiency in Chinese
}

\author{
H. C. LAI, ${ }^{1}$ MICHAEL P. Y. LAI, AND KEVIN S. N. LEUNG \\ From the Department of Pathology and Paediatrics, The University and Queen Mary Hospital, \\ Hong Kong
}

SYNOPSIS In a Chinese population 1,000 full-term male neonates and a further 117 jaundiced neonates of both sexes were studied in an investigation of the frequency of deficiency of erythrocyte. glucose-6-phosphate dehydrogenase(G6PD). This enzyme was found to be deficient in $3.6 \%$ of male neonates. Correlation of the results with the birthplace of the 602 mothers who were known to come from Kwangtung province showed no significant differences in the frequency of the deficiency between certain parts of the province.

The deficiency of G6PD in hemizygous males is profound but it is not associated with erythrocyte acid monophosphoesterase deficiency in Chinese in Hong Kong. The G6PD deficiency accounts for $\stackrel{0}{\frac{0}{2}}$ $15.4 \%$ of all the 117 cases of neonatal jaundice. The relative importance of G6PD deficiency as a cause of neonatal jaundice does not differ materially in male and female mutants. Neonatal jaundice $\mathscr{\odot}$ can occur in all genotypes of G6PD mutation in Chinese.

Glucose - 6 - phosphate dehydrogenase (G6PD) deficiency is one of the most prevalent and clinically heterogenous of the genetically determined enzyme disorders in man. In widely diverse ethnic groups it varies in incidence and manifestations (Marks, 1964), but the mechanism responsible for these disparities is unknown. They may reflect fundamental differences in disordered structure and synthesis of G6PD among different races and individuals (Kirkman, Schettini, and Pickard, 1964).

Chan, Todd, and Wong (1965) demonstrated that the severity of G6PD deficiency and the extent of cellular involvement are similar in Chinese and Caucasians. The enzyme defect is associated with neonatal hyperbilirubinaemia, congenital nonspherocytic haemolytic anaemia and favism in Chinese (Jim and Chu, 1963; Naiman and Kosoy, 1964; Yue and Strickland, 1965), but the clinical and biochemical characteristics of G6PD deficiency have not been fully investigated in this race as yet.

This report is a study of the incidence and severity of G6PD deficiency among the neonatal male Chinese population of Hong Kong and of the relative importance of the enzyme defect in causing neo-

${ }^{1}$ Present address: Department of Pathology, School of Medicine, University of Miami, Miami, Florida 33152, U.S.A.

Address requests for reprints to Dr. H. C. Lai, Department of Pathology, University of Hong Kong, Hong Kong.

Received for publication 24 May 1967. natal jaundice. The activity of erythrocyte acid monophosphoesterase (AMPE) in neonates with $\frac{\circ}{\Phi}$ normal G6PD activity is compared with that of G6PD-deficient neonates.

\section{MATERIAL AND METHODS}

One thousand full-term neonates delivered consecutively in the Queen Mary Hospital, Hong Kong, were studied. $\frac{\text { O }}{8}$ A further group of 117 neonates of both sexes admitted $\overline{0}$ on account of jaundice to the paediatric wards of the Queen Mary Hospital was also studied: the second group 8 included some babies from the first group. All the babies 3 were Chinese. Erythrocyte G6PD activity was screened by the methaemoglobin reduction test (Brewer, Tarlov, $\frac{}{7}$ and Alving, 1962) and positive results in this test were $\frac{D}{2}$ checked by the brilliant cresyl blue test (Motulsky and Campbell-Kraut, 1961). Actual activity of G6PD was N assayed by Prankerd's modification of the Hornberg and Horecker spectrophotometric determination of the $N$ reduced nicotinamide adenine-dinucleotide-phosphate $N$ generation rate (Prankerd, 1962). Enzyme activity was expressed as units of change in optical density per minute per gram of haemoglobin (U.O.D. $340 \mathrm{~m} \mu / \mathrm{min} . / \mathrm{g} . \stackrel{\varrho}{\overparen{D}}$
haemoglobin).

The activity of erythrocyte AMPE was assayed by the $\stackrel{\mathscr{?}}{?}$ method of King, Wood, and Delory (1945) as slightly modified by Oski, Shahidi, and Diamond (1963), the substrate, disodium phenylphosphate, being used in a $\stackrel{\mathbb{D}}{\circ}$ concentration of $1.11 \mathrm{~g} . / 100 \mathrm{ml}$. instead of $0.01 \mathrm{M}$ as in $\mathbb{D}$ the original method. The enzyme activity was expressed as units of milligrams of phenol hydrolysed per hour per 
gram of haemoglobin (U. mg./hr./g. haemoglobin). To determine the $p \mathrm{H}$ activity curve of this enzyme, acetate buffer solution of $0.05 \mathrm{M}$ was prepared to cover the range pH 3.6 to $7 \cdot 0$.

The erythrocyte G6PD activity was also assayed in the other members of the families of the 19 of the G6PDdeficient neonates of which 13 cases were discovered in the jaundiced and six in the non-jaundiced groups.

\section{RESULTS}

Thirty-six out of the 1,000 full-term male neonates studied showed deficiency of G6PD in both the methaemoglobin reduction and the brilliant cresyl blue decolorization tests. In all 36 cases the results were confirmed by assay of the actual activity of G6PD. The incidence of this enzyme defect in the Chinese male population studied was, therefore, $3.6 \%$. Among the mothers of these 1,000 neonates, 602 were known to be natives of Kwangtung, the most southerly province of China and adjoining Hong Kong. Seventeen of these 602 neonates were deficient in G6PD: the incidence of G6PD deficiency in this sample of male population of Kwangtung origin was thus about $2 \cdot 8 \%$. Further analysis of the incidence of G6PD deficiency in babies whose mothers came from particular districts of Kwangtung revealed no noteworthy difference between the districts of Sz Yap (Pearl River Delta area) and Chiu Chau (the eastern part of Kwangtung province): the incidence for each district was respectively $2.75 \%$ (12 deficient cases among 440 newborns) and $2.85 \%$ (three deficient cases among 103 newborns). No conclusion can be drawn regarding the incidence of G6PD deficiency elsewhere in the province because too few of the cases originated in districts other than those named.

The actual activity of G6PD was determined and compared in 32 normal and 25 affected male neonates. In normal neonates the enzyme level ranged from 6.00 to 12.40 U.O.D. $340 \mathrm{~m} \mu / \mathrm{min}$./g. haemoglobin with a mean of $8.87 \pm 1.84$ U.O.D. 340 $\mathrm{m} \mu / \mathrm{min}$.g. haemoglobin. In the G6PD-deficient male neonates the enzyme level ranged from 0.0 to 0.075 U.O.D. $340 \mathrm{~m} \mu / \mathrm{min}$. g. haemoglobin with an average of $0.006 \pm 0.017$ U.O.D. $340 \mathrm{~m} \mu / \mathrm{min} . / \mathrm{g}$. haemoglobin.

The frequency of G6PD deficiency as a cause of neonatal jaundice in Chinese was studied in 117 jaundiced neonates (64 male and 53 female). Deficiency of G6PD was demonstrated in 18 jaundiced neonates (10 male and eight female): G6PD deficiency thus accounted for about $15.4 \%$ of neonatal jaundice in the cases studied. The frequencies of G6PD deficiency as a cause of neonatal jaundice do not differ significantly between males $(15.6 \%)$ and females $(15 \cdot 1 \%)$.
The results of investigating the families of 13 jaundiced and six spontaneously delivered G6PDdeficient neonates are summarized in Table $I$, and the enzyme activities in the members of six G6PDdeficient neonates' families are illustrated in Figure 1.

\section{TABLE I}

INHERITANCE PATTERN OF G6PD DEFICIENCY IN CHINESE NEONATES

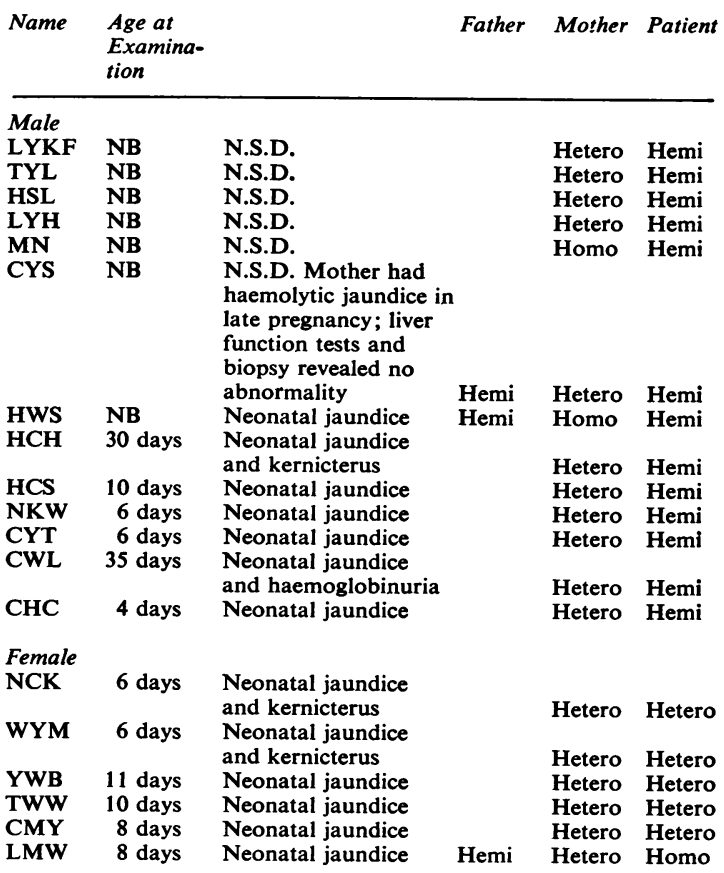

NB $=$ Newborn. N.S.D. = Normal spontaneous delivery. Hetero $=$ Heterozygote. Homo $=$ Homozygote. Hemi $=$ Hemizygote.

Females giving a positive result in screening tests but retaining some activity as shown by actual determination were considered to be partially deficient in the enzyme and were classified as heterozygotes of the abnormal G6PD gene: the enzyme level of 20 heterozygous female (16 mothers and four neonates) studied ranged from 4.0 to 4.9 U.O.D. $340 \mathrm{~m} \mu / \mathrm{min}$. $/ \mathrm{g}$. haemoglobin with a mean of $4.48 \pm 0.48$ U.O.D. $340 \mathrm{~m} \mu / \mathrm{min} . / \mathrm{g}$. haemoglobin. Females showing a positive result in screening tests and no enzyme activity on actual determination were considered to be completely deficient in this enzyme and were classified as homozygotes of the abnormal G6PD gene. The results of familial investigation confirm that this enzyme defect is inherited as an X-linked trait in Chinese: 16 out of 18 mothers studied were identified as heterozygotes and two homozygotes of the abnormal G6PD gene while three out of the 18 

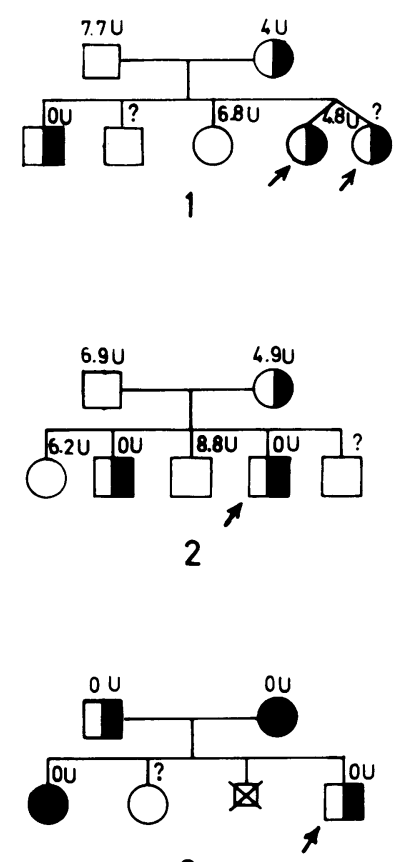

3
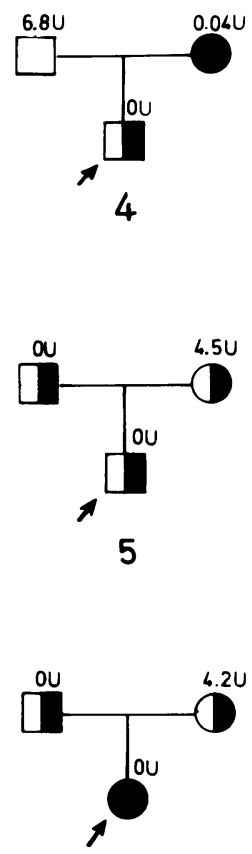

6

FIG. 1. Inheritance pattern of glucose-6-phosphate dehydrogenase deficiency in Chinese families.

(1) Propositi (NYM and NCK, female/6 days) are twins, showing neonatal jaundice and kernicterus.

(2) Propositus ( $C W L$, male/35 days) shows haemolytic jaundice and haemoglobinuria.

(3) Propositus (HWS, male/neonate) shows haemolytic jaundice exchange transfusion.

(4) Propositus (MN, male/neonate).

(5) Propositus (CYS, male/neonate) Mother had haemolytic jaundice in late pregnancy.

(6) Propositus (LMW, female/8 days) shows haemolytic jaundice.

Activity of G6PD expressed in U.O.D. $340 \mathrm{m \mu} / \mathrm{min} . / \mathrm{g}$. haemoglobin.

fathers studied were identified as hemizygotes of the abnormal G6PD gene, and the remainders were normal in G6PD activity. However, an interesting point is shown from the familial investigation that neonatal jaundice occurs quite commonly in heterozygous females: among six jaundiced female neonates, five were demonstrated as heterozygotes and one homozygote of the abnormal G6PD gene.

Measurement of erythrocyte AMPE activity was carried out on 31 male neonates with normal G6PD and in 14 deficient in this enzyme. In the normal group the AMPE level ranged from $29 \cdot 30$ to $43.75 \mathrm{U}$. $\mathrm{mg} . / \mathrm{hr} . / \mathrm{g}$. haemoglobin with a mean of $36 \cdot 67 \pm$ $3.75 \mathrm{U} . \mathrm{mg} . / \mathrm{hr} / \mathrm{g}$. haemoglobin. In the deficient group the AMPE level ranged from 24.00 to

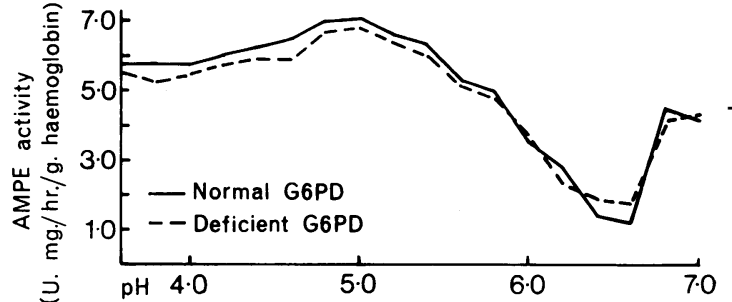

FIG. 2. $\mathrm{pH}$ activity curve of erythrocyte acid monophosphoesterase in a normal neonate and in a neonate deficient in G6PD.

$42 \cdot 80 \mathrm{U} . \mathrm{mg} . / \mathrm{hr} . / \mathrm{g}$. haemoglobin with an average of $33.64 \pm 0.40$ U. mg./hr./g. haemoglobin. Application of the $t$ distribution test showed that the

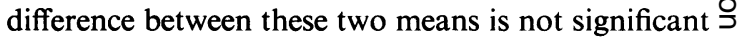
$(0.0475>\mathrm{p}>0.045)$. To confirm this, the $p \mathrm{H} \vec{c}$ activity curve of the AMPE was compared in five normal and from a G6PD-deficient neonate: there $\frac{\vec{D}}{\mathrm{D}}$ is only one peak of activity in the $p \mathrm{H} 4 \cdot 8$ to $5 \cdot 0$ range and the curves are exactly alike in their whole $\vec{\oplus}$ courses (Fig. 2).

\section{DISCUSSION}

Racial differences in clinical and biochemical characteristics of G6PD deficiency have been known $\stackrel{2}{2}$ for a long time. Neonatal hyperbilirubinaemia, $\stackrel{\varnothing}{\varrho}$ congenital nonspherocytic haemolytic anaemia, and $\overrightarrow{\vec{O}}$ favism have never been reported in G6PD-deficient $\frac{3}{3}$ Negroes but are known to occur in G6PD-deficient Caucasians (Zinkham, Lenhard, and Childs, 1958; Doxiadis, Fessas, and Valaes, 1960; Doxiadis, Fessas, Valaes, and Mastrokalos, 1961 ; Kirkman and Riley, 1961). The enzyme deficiency in Caucasian hemizygotes is much greater than in Negro hemizygotes. Further, the deficiency involves non- $\frac{0}{3}$ nucleated as well as nucleated cells in Caucasians, whereas nucleated cells are not affected in Negroes (Marks and Gross, 1959; Ramot, Szeinberg, Adam, $\frac{7}{0}$ Sheba, and Gafni, 1959; Gartler, Gandini, and Ceppellini, 1962; Wurzel, McCreary, Baker, and N Gumerman, 1961; Zinkham, 1961). Oski et al. (1963) found that G6PD deficiency is associated with a defect in activity of erythrocyte AMPE in Caucasians $\omega$ but not in Negroes. Electrophoretic studies of erythrocyte G6PD demonstrates two phenotypes of G6PD, slow and fast. Negro mutants are always of $\mathbb{\Phi}^{\Phi}$ the slow A phenotype, whereas a small proportion? of Caucasian mutants are of the fast $B$ phenotype $\frac{7}{3}$ (Boyer, Porter, and Weilbacher, 1962; Kirkman and $\underset{\mathbb{D}}{\circ}$ Hendrickson, 1963). Clinical and laboratory observa- $\stackrel{?}{\mathbb{D}}$ tions have revealed close similarity in the manifesta- $\stackrel{\mathbb{Q}}{\mathcal{Q}}$ tions, severity, and extent of tissue involvement in 
G6PD deficiency in Caucasians and in Chinese. However, recent studies of the physicochemical properties of G6PD have shown dissimilarities between the two races in the electrophoretic mobility, thermolability, optimum $p \mathrm{H}$ activity curve, Michaelis constant for glucose-6-phosphate, and nicotinamide adenine-dinucleotide-phosphate, and usage of substrate analogues (Wong, Shih, Hsia, and Tsao, 1965; McCurdy, Kirkman, Naiman, Jim, and Pickard, 1966). Consideration of all these facts, together with the modifying effects of the environmental and secondary genetic factors to which these two geographically widely separate races have been exposed in their long history, makes complete identity in all characteristics of G6PD deficiency in Caucasians and Chinese highly unlikely: difference in some of the clinical or biochemical manifestations will doubtless be defined in due course.

Our study shows no difference in the activity of erythrocyte AMPE in normal and G6PD-deficient Chinese. A racial difference may exist in this respect, for Oski et al. (1963) reported that AMPE deficiency was associated with G6PD deficiency in Caucasians. The authors considered this to be a consistent biochemical difference between Caucasian and Negro mutants, but their finding has not been confirmed by other investigators and its value as a criterion for differentiating G6PD deficiency in these two races remains doubtful.

In estimating the gene frequency of G6PD deficiency in the general population, it is customary to choose male subjects for screening tests. This is because the results of screening tests sometimes appear doubtful in heterozygous females, a proportion of whom may escape detection by conventional screening methods. The incidence of deficiency of G6PD in male Chinese populations was reported as $3.74 \%$ by Yue and Strickland (1965) and as $5.5 \%$ by Chan, Todd, and Wong (1964). The disparity between those figures probably arises because Yue and Strickland studied the deficiency among neonates, whereas Chan and his co-workers studied adult hospital inpatients. The $3.6 \%$ incidence of G6PD deficiency in male neonates in our study is very close to that of Yue and Strickland. Our study has also indicated that the incidence does not differ materially between certain parts of Kwangtung Province in which different dialects are spoken.

Our results also show that G6PD deficiency accounts for about $15.4 \%$ of cases of neonatal jaundice warranting admission to hospital among Chinese in Hong Kong. Over the past three years in our hospital $55 \%$ of the cases of kernicterus have been deficient in the enzyme. Wong (1965) found that nearly $50 \%$ of kernicterus among Chinese in Singapore is due to G6PD deficiency. Since the enzyme level in male mutants is usually much lower than that in female mutants, one might postulate that G6PD deficiency is a more important cause of neonatal jaundice in male mutants than in female mutants. In Greece the sex ratio of neonatal jaundice due to G6PD deficiency was reported as three males to one female (Motulsky, 1965). Our findings indicate that this is not true in Chinese, however: the relative importance of the enzyme defect does not differ significantly in male and female jaundiced neonates, and neonatal jaundice occurs in all types of mutants. Thus the haemolytic process in G6PD mutants is not related directly to the level of enzyme activity. Other factors which help to determine the occurrence of the haemolysis must be sought in individual cases with the defect.

We are extremely grateful to Professor J. B. Gibson, and Professor E. C. Field, University of Hong Kong, for their continued help and stimulation in this study. Special thanks are due to Dr. Lopez for his cooperation in providing the specimens for this study and to Dr. J. Grant for his valuable advice. Our sincere appreciation is also due to Miss K. L. Leung and Mr. M. Chan.

\section{REFERENCES}

Boyer, S. H., Porter, I. H., and Weilbacher, R. G. (1962). Proc. nat. Acad. Sci. (Wash.), 48, 1868.

Brewer, G. J., Tarlov, A. R., and Alving, A. S. (1962). J. Amer. med. Ass., 180, 386.

Chan, T. K., Todd, D., and Wong, C. C. (1964). Brit. med. J., 2, 102. _- - (1965). J. Lab. clin. Med., 66, 937.

Doxiadis, S. A., Fessas, P., and Valaes, T. (1960). Lancet, 2, 44. , , and Mastrokalos, N. (1961). Ibid., 1, 297.

Gartler, S. M., Gandini, E., and Ceppellini, R. (1962). Nature (Lond.), 193, 602.

Jim, R. T. S., and Chu, F. K. (1963). Pediatrics, 31, 1046.

King, E. J., Wood, E. J., and Delory, G. E. (1945). Biochem. J., $39,24 \mathrm{P}$.

Kirkman, H. N., and Riley, H. D., Jr. (1961). Amer. J. Dis. Child., 102, 313.

-, Schettini, F., and Pickard, B. M. (1964). J. Lab. clin. Med. 63, 726 .

, and Hendrickson, E. M. (1963). Amer. J. hum. Genet., 15, 241

Marks, P. A., and Gross, R. T. (1959). J. clin. Invest., 38, 2253.

(1964). In The Red Blood Cell, edited by C. Bishop and D. M Surgenor, p. 211. Academic Press, New York and London.

McCurdy, P. R., Kirkman, H. N., Naiman, J. L., Jim, R. T. S., and Pickard, B. M. (1966). J. Lab. clin. Med., 67, 374.

Motulsky, A. G., and Campbell-Kraut, J. M. (1961). In Proceedings of the Conference on Genetic Polymorphisms and Geographic Variations in Disease, edited by B. S. Blumberg, p. 159. Grune and Stratton, New York.

- (1965). In Abnormal Haemoglobin in Africa, edited by J. H. P. Jonxis, p. 143. Blackwell Scientific Publications, Oxford.

Naiman, J. L., and Kosoy, M. H. (1964). Canad. med. Ass. J., 91, 1243.

Oski, F. A., Shahidi, N. T., and Diamond, L. K. (1963). Science, 139, 409.

Prankerd, T. A. J. (1962). Ass. clin. Pathol. Broadsheets, no. 42.

Ramot, B., Szeinberg, A., Adam, A., Sheba, C., and Gafni, D. (1959). J. clin. Invest., 38, 1659.

Wong, P. W. K., Shih, L. Y., Hsia, D. Y. Y., and Tsao, Y. C. (1965). Nature (Lond.), 208, 1323.

Wong Hock Boon (1965). J. Singapore paediat. Soc., 7, 35.

Wurzel, H., McCreary, T., Baker, L., and Gumerman, L. (1961). Blood, 17, 314

Yue, P. C. K., and Strickland, M. (1965). Lancet, 1, 350.

Zinkham, W. H. (1961). Bull. Johns Hopk. Hosp., 109, 206.

-, Lenlard, R. E., Jr., and Childs, B. (1958). Ibid., 102, 169. 